\title{
Citologia de impressão da superfície ocular: técnica de exame e de coloração
}

\author{
Impression cytology of theocular surface:examination techniqueand staining procedure
}

\author{
Jeison de Nadai Barros ${ }^{1}$ \\ Vera Lucia Degaspare Monte Mascaro ${ }^{2}$ \\ José Álvaro Pereira Gomes ${ }^{3}$ \\ Denise de Freitas ${ }^{4}$ \\ Ana Luisa Hofling de Lima ${ }^{5}$
}

\begin{tabular}{|l|}
\hline \multicolumn{1}{|c|}{ RESUMO } \\
\hline Objetivo: Apresentar uma técnica de exame e de coloração de amostras de \\
citologia de impressão da superfície ocular desenvolvida em serviço de \\
referência. Método: Obtiveram-se28 amostras de citologia de impressão de \\
pacientes com alterações da superfície ocular no Setor de Doenças \\
Externas Oculares no período de julho a novembro de 1999. Coraram-se e \\
avaliaram-se as amostras microscopicamente no Laboratório de \\
Microbiologia Ocular, do Departamento de Oftalmologia da Universidade \\
Federal de São Paulo - Escola Paulista Medicina. Resultados: Desenvol- \\
veu-se um modelo de papel de filtro com ápice, base e abertura lateral, que \\
forneceu seu posicionamento correto no olho no momento da colheita e \\
na lâmina para a fixação e coloração. A técnica de coloração descrita, que \\
usa ácidoperiódico-Schiff, hematoxilina ePapanicolaou,é umprocedimen- \\
to economico e fácil, cora as células caliciformes de róseo e as epiteliais de \\
roxo. Conclusões: A técnica de exame mostrou-se ideal na avaliação celular \\
das amostras de citologia de impressão. A citologia de impressão é um \\
método bastante confiável para o estudo da superfície ocular, no acompa- \\
nhamento da evolução de patologias externas, e provou ser um procedi- \\
mento realmente simples, mais barato e mais confortável para o paciente \\
que as biópsias invasivas.
\end{tabular}

Descritores: Técnicas citológicas; Córnea; Conjuntiva/citologia; Citodiagnóstico/métodos; Coloração/métodos

\section{INTRODUÇ̃̃̃O}

A citologia de impressão consiste em um método não invasivo para avaliação da superfície ocular, que inclui o epitélio da conjuntiva e da córnea $^{(1)}$. Representa uma alternativa em relação à citologia obtida com raspados da superfície ocular, além de garantir uma melhor qualidade das amostras. O papel filtro, quando aplicado sobre a superfície córneo-conjuntival, remove amostras que contém de uma a três camadas de células epiteliais, e preserva principalmente as características morfológicas e as relações anatômicas das células obtidas ${ }^{(2)}$. As amostras são fixadas, coradas e examinadas em laboratório, usando-se um método modificado para a citologia da superfície ocular. Esta técnica auxilia o entendimento e direciona o tratamento das afecções da superfície ocular, pois permite a análise do grau de metaplasia escamosa, contagem do número de células caliciformes em casos de olho seco, hipovitaminose A, deficiência límbica corneal (síndrome de Stevens-Johnson, penfigóide ocular, queimaduras) ${ }^{(3)}$; utiliza-se como método de análise microbiológica (viral) ${ }^{(4-5)}$ e na avaliação da superfície ocular em pacientes usuários de lente de contato ${ }^{(6)}$, em bebês prematuros $^{(7)}$, e em pacientes diabéticos ${ }^{(8)}$. 
Apresenta-se neste trabalho um procedimento simples e eficaz que pode ser utilizado como rotina para o diagnóstico citológico de afecções de superfície ocular.

\section{MÉTODOS}

Obtiveram-se vinte e oito amostras de citologia de impressão da superfície ocular de pacientes adultos, portadores de alterações, de julho a novembro de 1999, com finalidade de padronizar o exame de citologia de impressão. O papel filtro usado foi da Millipore Corporation, código de catálogo HAWP304F0, com poro de $0,45 \mu \mathrm{m}$. Cortou-se manualmente com uma tesoura e segurou-se o papel filtro apenas com pinça de extremidade suave. O contato direto dos dedos com o papel aderiria células da polpa digital na sua superfície. Desenvolveu-se um modelo de papel, de aproximadamente $5 \mathrm{~mm}$ de largura $\times 7 \mathrm{~mm}$ de altura com ápice, base e abertura lateral (Figura 1), para indicar o posicionamento correto na lâmina (epitélio para cima). Nesta técnica, o "imprint" continua no papel onde é fixado, corado e avaliado. Esse formato do papel permite que a citologia de impressão realize-se em qualquer quadrante da superfície ocular mantendo sua orientação em todas as lâminas.

Aplica-se a ponta do papel (ápice), de acordo com a figura 2, sobre a córnea, posiciona-se a abertura lateral próxima ao limbo e a base sobre a conjuntiva.

O papel filtro foi esterilizado em óxido de etileno. Após anestesia tópica e colocação do blefarostato para exposição do olho, aplicou-se o papel filtro em um ou mais quadrantes diferentes da superfície ocular com uma pinça de extremidade aplanada e suave. O papel filtro deve ser pressionado por um período de 2 a 5 segundos em toda sua extensão para garantir uma boa colheita de células. Removeu-se o papel filtro com a mesma pinça, por meio de manobra de "peeling" e posicionou-se sobre uma lâmina limpa para ser imediatamente fixado por 10 minutos com solução preparada previamente com $100 \mathrm{ml}$ de álcool etílico a $70 \%, 5 \mathrm{ml}$ de ácido acético glacial e $5 \mathrm{ml} \mathrm{de}$ formaldeído a $37 \%$. Identificou-se a lâmina da seguinte forma: anotou-se o número de registro do paciente no laboratório, o nome do paciente, o olho examinado (direito/esquerdo) e a área

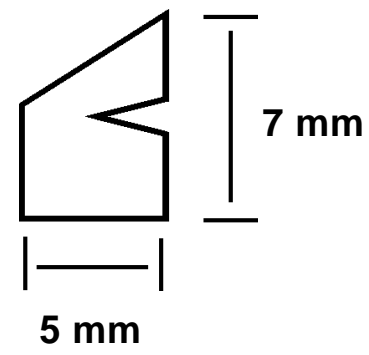

Figura 1 - Modelo e formato do papel filtro

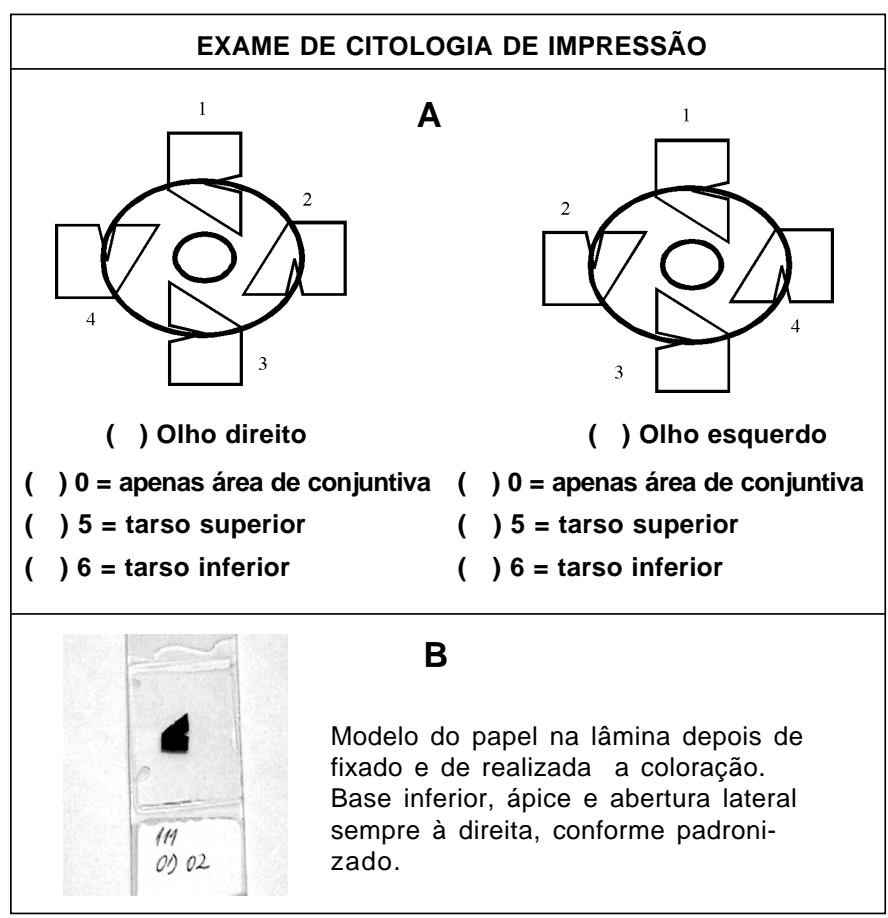

Figura 2 - A. Ficha de exame: técnica de posicionamento para colheita das amostras; B. Modelo do papel filtro corado e montado na lâmina

da colheita de acordo com os seguintes códigos numéricos: $1=$ quadrante superior, $2=$ quadrante nasal, $3=$ quadrante inferior, $4=$ quadrante temporal. Deve-se colocar o código 0 (zero) caso a área coletada seja apenas de conjuntiva e não inclua córnea. Adotou-se o código 5 para colheitas na conjuntiva tarsal superior e 6 para conjuntiva tarsal inferior.

Após devidamente identificada, a lâmina foi colocada em uma placa de Petri e estocou-se até realizar-se a coloração. Neste estudo, realizou-se a coloração no mesmo dia da colheita ou até 18 dias após colher-se a amostra. Porém, a maioria das colorações foi realizada no quinto dia após a obtenção das amostras.

Para a coloração, removeu-se com uma pinça cada papel estocado, e colocou-se em uma célula de cassete próprio para coloração histológica, com 48 lugares de aproximadamente $7 \mathrm{x}$ $7 \mathrm{~mm}$ cada. A técnica de coloração deste estudo baseou-se na técnica de citologia de impressão de Martinez et al..$^{(1)}$, que usa ácido periódico de Schiff(PAS), hematoxilina e Papanicolaou modificado, com algumas alterações.

Coloração das amostras: mergulhou-se o cassete, com os papéis, em recipientes estreitos que continham as soluções descritas abaixo. A nossa técnica consistiu em:

- Rehidrataram-se as amostras em álcool etílico a 70\% por 2 min. Mergulharam-se em água de torneira por 20 vezes e em água destilada por mais 20 vezes.

- Imergiram-se as amostras totalmente em solução de acido periódico a $0,5 \%$ por 2 min e depois mergulharamse em água destilada por 20 vezes. 
- Preparou-se uma solução recente de reagente de Schiff na proporção de 1:3 com água destilada e deixaram-se as amostras imersas por $2 \mathrm{~min}$, depois mergulharam-se 20 vezes em água de torneira.

- Deixaram-se agora em solução de metabissulfito de sódio a $0,5 \%$ por 2 min e então lavaram-se com 20 mergulhos em água de torneira.

- Deixaram-se as amostras durante um minuto em solução de Hematoxilina de Harris, lavaram-se em seguida com 20 mergulhos em água de torneira.

- Mantiveram-se agora mantidas imersas por $2 \mathrm{~min}$ na solução preparada de substituto de "água tap de Scott" por 2 min, lavaram-se em seguida com 20 mergulhos em água de torneira. Substituto de "água tap de Scott" é uma mistura de $1000 \mathrm{ml}$ de água torneira, $2 \mathrm{~g}$ de bicarbonato de sódio e $10 \mathrm{~g}$ de sulfato de magnésio

- Imergiram-se as amostras por 30 segundos para desidratar no álcool etílico a 95\%.

- Colocaram-se agora por 2 min em solução de Orange G e depois por 3 min em álcool etílico a $95 \%$.

- Imergiram-se por 2 min em EA 36 (Papanicolaou) e depois por 10 min em álcool etílico a $95 \%$.

- Desidrataram-se as amostras com álcool absoluto por 2 min. Trocou-se a solução e deixaram-se por mais $3 \mathrm{~min}$.

- Transferiram-se para o Xilol em duas passagens, de 7 e 8 minutos. Este é o processo de diafanização.

- Reposicionou-se o papel filtro em cada lâmina, mantendo-se a face do papel com o epitélio voltado para cima, montou-se com Entellan, e colocou-se uma lamínula como cobertura de proteção. O processo foi realizado respeitando-se a imersão completa das amostras nas soluções e de acordo com o tempo e número de vezes recomendados. Analisou-se o papel sob microscopia óptica.

\section{RESULTADOS}

A técnica, que utilizou o modelo de papel por nós desenvolvido, garantiu o seu posicionamento adequado no olho, no momento da colheita e na lâmina para a fixação e coloração.

Observou-se presença de células em todos os espécimes colhidos, em quantidades variadas, dependendo da doença e lubrificação do olho. Notou-se que nos olhos com excesso de lacrimejamento obtiveram-se piores resultados na colheita do material, prejudicando o resultado final do exame.

$\mathrm{O}$ ácido periódico de Schiff (PAS) corou as células caliciformes da conjuntiva de róseo, o que possibilitou identificar seu núcleo acêntrico e seu grande tamanho. As células epiteliais da conjuntiva são menores, com núcleo basofílico e coram-se em roxo devido à hematoxilina.

Sob microscopia óptica e com aumentos variados, analisou-se cada lâmina quanto à presença ou ausência de células caliciformes, e morfologia de células epiteliais. A amostra ideal, considerando-se que houve boa colheita e coloração padronizada, apresentou um número adequado de células morfologicamente bem preservadas, o que permitiu se observar, à microscopia óptica, a anatomia das células relativas à área desejada. (Figuras 3 e 4).

\section{DISCUSSÃO}

A técnica de exame e de coloração tem que ser padronizada para que se obtenha reprodutibilidade. A citologia de impressão da superfície ocular é um exame oftalmológico que consiste das seguintes etapas: colheita, fixação, coloração, montagem e análise microscópica. A colheita das amostras foi realizada pelos médicos envolvidos neste estudo.

Assim como concluíram Egbert et al. ${ }^{(9)}$, ao introduzir a técnica em 1977, também observamos que os filtros da Millipore, que misturam ésteres de celulose, oferecem os melhores resultados. O papel filtro com poro de $0,45 \mu \mathrm{m}$ está de acordo com o usado pela maioria dos autores na literatura, que segundo Dart $^{(2)}$, varia de 0,22 a $0,45 \mu \mathrm{m}$.

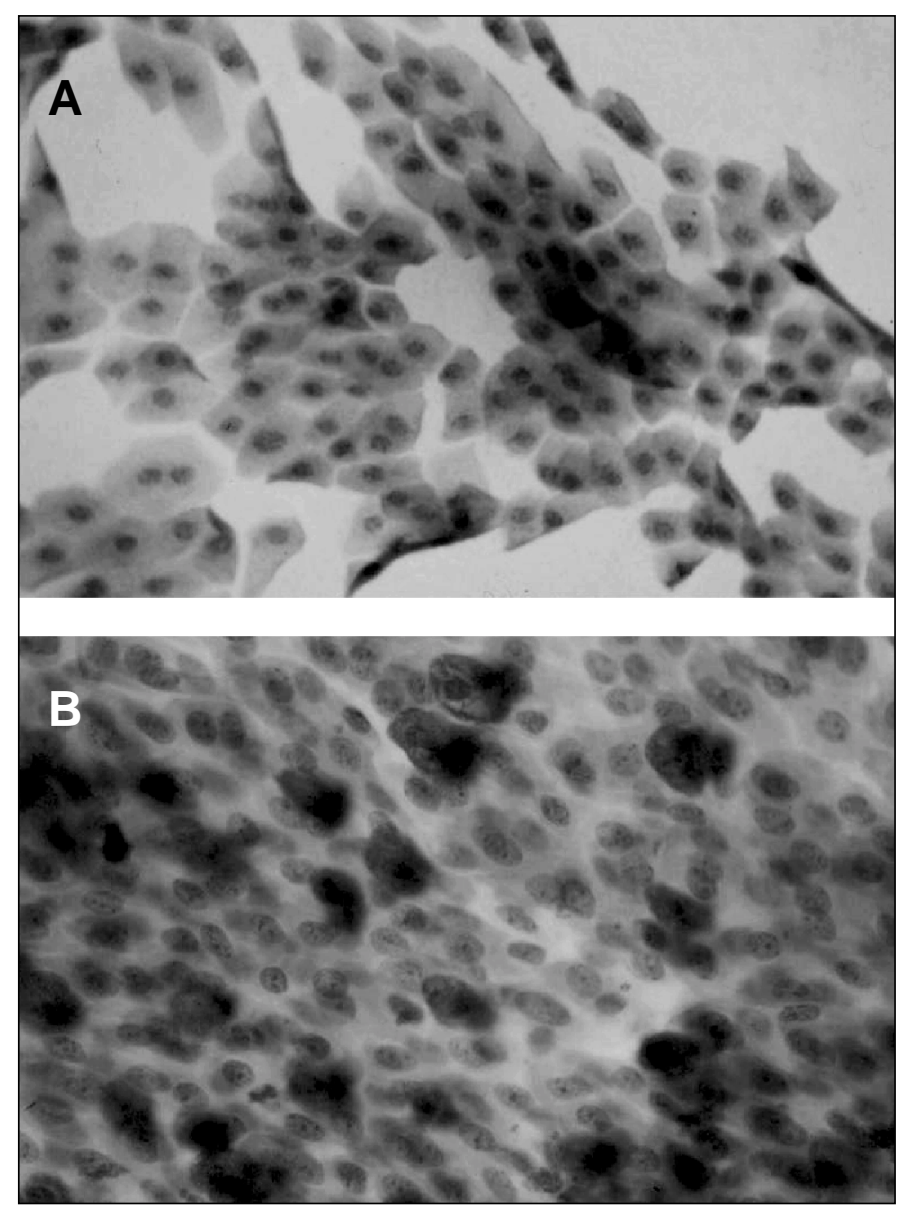

Figura 3 - A. Fotomicrografia de citologia de impressão obtida de conjuntiva bulbar nasal de paciente com olho seco. Ausência de células caliciformes e células epiteliais com leve perda da adesão e algumas com tamanho aumentado. (PAS/HE/Papanicolaou MO 200x). B. Fotomicrografia com exemplo de citologia de impressão obtida de conjuntiva normal, para efeito de comparação. Presença de várias células caliciformes e epitélio com células bem aderidas. (PAS/HE Papanicolaou MO 400x) 

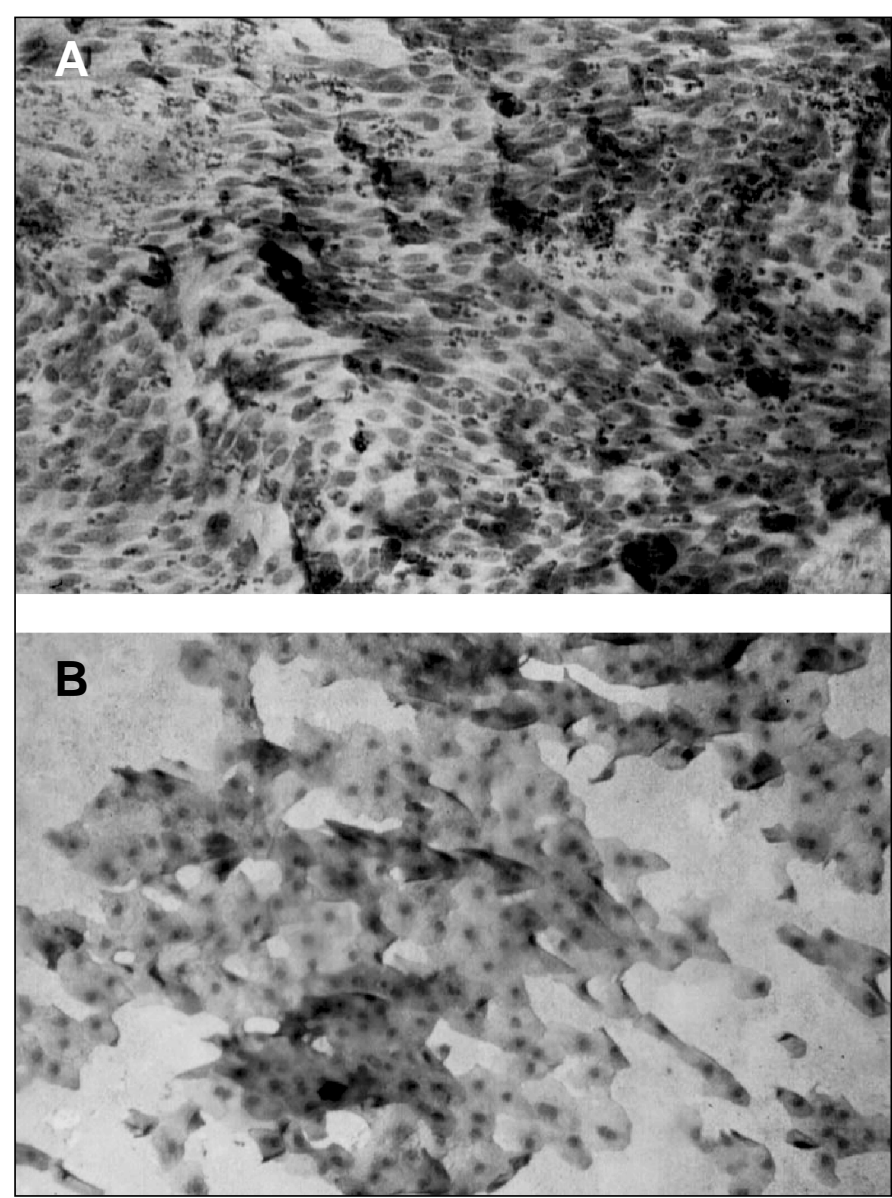

Figura 4 - A. Fotomicrografia de citologia de impressão obtida de córnea de paciente com queimadura ocular por álcali. Presença de células epiteliais com aspecto conjuntival (relação núcleo citoplasmática de 1:2), presença de "imprints" de mucina e presença de neutrófilos. (PAS/HE/Papanicolaou MO 200x). B. Fotomicrografia com exemplo de citologia de impressão obtida de córnea normal, para efeito de comparação. Presença de células epiteliais e ausência de células caliciformes. (PAS/HE/Papanicolaou MO 100x)

O procedimento de coloração consiste em processo de múltiplos passos destinado a corar células da superfície ocular de modo a facilitar a diferenciação dos vários estágios de mudanças epiteliais. Não há estudos na literatura que avaliem o melhor intervalo de tempo entre a colheita da amostra e a coloração do papel. Entretanto, a maioria das colorações realizou-se no quinto dia após a colheita, neste estudo. É importante ressaltar que nossa técnica difere de alguns autores como Gadkari et al. ${ }^{(10)}$, que transferem as células obtidas no papel para uma lâmina para serem fixadas e coradas.

Martinez et al..$^{(1)}$, em seu estudo, referem que a hematoxilina deve ser filtrada antes do seu uso para eliminar precipitados. Em nosso estudo, realizou-se a coloração com a freqüência de uma vez por semana, observamos que a hematoxilina estocada em ótimas condições de conservação, seguindo-se as instruções do fabricante, permaneceu sem precipitados por sete meses. Atualmente, utilizamos a filtragem antes de todas as colorações.

Diante do conhecimento de que o PAS é corante que se "contamina" ou deteriora com muita facilidade, isto é, pode perder o efeito se substâncias impuras se misturarem à sua composição, optamos por lavar as amostras em água destilada antes de mergulhá-las em solução de ácido periódico a $0,5 \%$. Ainda para evitar qualquer contaminação do corante, trocamos a lavagem das amostras em água de torneira, antes da imersão em solução de reagente de Schiff, por lavagem em água destilada. A hematoxilina usada em nosso protocolo para corar foi a hematoxilina de Harris, enquanto que o sugerido por Martinez et al. ${ }^{(1)}$ era a hematoxilina de Gill. Em uma etapa de desidratação em álcool etílico a $95 \%$ preferimos deixar os espécimes em imersão por 30 segundos, ao invés de mergulhá-los 10 vezes na solução, repetindo-se a operação.

O protocolo de Martinez et al.(1) usava tanto orange-G quanto EA modificados com a adição de outros reagentes. Em nosso estudo utilizamos, nas etapas necessárias, respectivamente, orange-G 6 puro e EA-36 (Papanicolaou). Na etapa de desidratação com álcool absoluto optamos por dividir a imersão em dois tempos: o primeiro com dois minutos e outro, com nova solução de álcool absoluto, de mais três minutos. Isto baseou-se em citações de Michalany ${ }^{(1)}$ que recomenda a troca do álcool do qual se conheça a graduação e nunca reutilizar alcoóis pois conforme o álcool desidrata o espécime, a água dilui a solução e a graduação do álcool vai baixando. A renovação do álcool é válida porque a água é assim eliminada. Foi com base nessas idéias que dividiu-se o tempo de diafanização pela ação do xilol, isto é, a retirada do álcool presente no espécime pela ação de solventes orgânicos. Dividimos o tempo de diafanização de quinze minutos em um de sete e outro com nova solução de oito minutos. As soluções depois de usadas são totalmente desprezadas.

Assim como notaram Reim et al. ${ }^{(12)} \mathrm{em}$ um de seus estudos, também notamos que o papel filtro tornou-se transparente nos solventes orgânicos, na etapa de diafanização do processo de coloração.

\section{CONCLUSÃO}

Concluímos que a citologia de impressão é um método bastante confiável para o estudo da superfície ocular, no diagnóstico e acompanhamento da evolução de patologias externas. Provou ser realmente simples e um procedimento mais barato e mais confortável para o paciente que as biópsias invasivas. Os resultados clínicos serão reportados futuramente.

\section{ABSTRACT}

Purpose: To present an examination technique and to standardize the staining procedure of samples of impression cytology of the ocular surface in a reference service. Methods: 28 samples of impression cytology were obtained from patients with ocular surfaces alterations of the External Eye Diseases Sector in the period of July to November 1999. They were stained and microscopically evaluated in the Ocular Microbiology Laboratory of the Federal University of São Paulo. Results: We developed a design of a filter paper with 
apex, base and lateral opening that promoted its adequate position both in the eye at collection and on the glass microscope slides for fixing and staining procedures. The staining technique that uses periodic acid-Schiff, hematoxilin and Papanicolaou is an easy and economic procedure which stains goblet and epithelial cells. Conclusions: The modified method for staining showed to be ideal for the cytologic evaluation of samples of the impression cytology examination. Impression cytology is a very reliable method to study ocular surface, and has proved to be really simple, a cheaper and more confortable procedure for the patient than invasive biopsies.

Keywords: Cytological Techniques; Cornea; Conjunctiva/ cytology; Cytodiagnosis/methods; Staining and labeling/ methods

\section{REFERÊNCIAS}

1. Martinez AJ, Mills MB, Jaceldo KB, Tio FO, Aigbivbalu IB, Hilsenbeck $\mathrm{SB}$, Yee RW. Standardization of conjuntival impression cytology. Cornea $1995 ; 14: 512-22$
2. Dart J. Impression cytology of the ocular surface - research tool or routine clinical investigation? Br J Ophthamol 1997;81:930.

3. Gomes JAP. Atualização no tratamento das ceratoconjuntivites cicatriciais. Arq Bras Oftal 2000;63:91-6.

4. Thiel MA, Bossart W, Bernauer W. Improved impression cytology techniques for the immunopathological diagnosis of superficial viral infections. Br J Ophthamol 1997;81:984-8.

5. Jackson JA, Perrigin JA. Relationship of impression cytology and tear ferning to reports of dry eye. J Am Optom Assoc 1999;70:187-92.

6. Adar S, Kanpolat A, Sürücü S, Ucakhan OO. Conjunctival impression cytology in patients wearing contact lenses. Cornea 1997;16:289-94.

7. Hughes AP, Shaw NJ, Southall P, Hero M, Bowden L, Young RH et al. Conjunctival impression cytology in the preterm infant and it's relation to outcome. J Pediatr 1997;156:471-5.

8. Meller D, Augustin AJ, Koch FH. A modified technique of impression cytology to study the fine structure of corneal epithelium. Ophthalmic Res 1996;28:71-9.

9. Egbert P, Lauder S, Maurice DM. A simple conjunctival biopsy. Am J Ophthalmol 1977;84:798-801.

10. Gadkari SS, Adrianwala SD, Prayag AS, Khinani P, Metha NJ, Saha NA. Conjunctival impression cytology - a study of normal conjunctiva. J Postgrad Med 1992;38:21-3.

11. Michalany J. Técnica histológica em anatomia patológica (com instruções para o cirurgião, enfermeira e citotécnico). São Paulo: Editora Michalany; 1990.

12. Reim M, Becker J, Genser C, Salla S. Assessment of conjunctival epithelium after severe burns and surgical reconstruction with tenon plasty by means of a modified impression cytology procedure. Cornea 1998;17:365-70.

\title{
XXIII CONGRESSO PAN-AMERICANO DE OFTALMOLOGIA
}

\author{
22 A 25 DE JULHO DE 2.001
}

\author{
Hotel Sheraton \\ Buenos Aires - Argentina
}

\section{Informações: Associação Panamericana de Oftalmologia Telf.: (001-817) 265-2831 - Fax: (001-817) 275-3961 e-mail:info@paao.org}

